\title{
Comunicação organizacional, tecnologias e vigilância: entre a realização e 0 sofrimento
}

\section{Rudimar Baldissera}

\section{Resumo}

Na perspectiva da Comunicação Organizacional, objetiva-se refletir sobre a tensão atualizada nos processos colaborativos, particularmente aqueles que se caracterizam por, mediante o emprego de tecnologias, dar visibilidade a conhecimento/ informações dos diferentes trabalhadores no âmbito de suas organizações, bem como sobre as apropriações que essas mesmas organizações fazem daquilo que é exposto. Nessa direção, pode-se pensar em processos que potencializam 0 conhecimento pela colaboração dos diferentes sujeitos, mas também nos de vigilância e controle sobre tais sujeitos. Atenta-se para o fato de que as organizações, como lugar de realização dos sujeitos, nesses mesmos processos, constituem-se, por um lado, como possibilidade de exposição qualificada desses sujeitos, gerando reconhecimento/prazer, e, por outro, de exposição desqualificada, gerando sofrimento (DEJOURS, 1996, 1999).

\section{Palavras-Chave}

Comunicação organizacional. Tecnologias digitais de comunicação e informação. Visibilidade.

Vigilância. Sofrimento.

Rudimar Baldissera | rudimar.baldissera@ufrgs.br Doutor em Comunicação pela Pontifícia Universidade Católica do Rio Grande do Sul (PUC-RS). Professor da Faculdade de Biblioteconomia e Comunicação - Departamento de Comunicação - Curso de Relações Públicas e do Programa de Pós-Graduação em Comunicação e Informação da Universidade Federal do Rio Grande do Sul (UFRGS).

\section{Sobre o contexto: sociedade e tecnologias}

Entre apologias e condenações, paixões e aversões; entre resistências de viés apocalíptico e integrações acríticas, a sociedade percebe-se tecida em tecnologias. Nesse elástico percurso de percepções e representações, as diferentes tecnologias apresentam-se constitutivas das novas sociabilidades assumindo centralidade cultural. Vivese a "sociedade em rede" que, de acordo com Castells (1999, p. 108-110), dentre outras coisas, caracterizase por ter a informação como matéria prima e, também, pelo fato de as tecnologias atravessarem e/ ou se instalarem em todas as atividades humanas, a lógica de redes realizar-se em todos os sistemas ou conjuntos de relações, por apresentar flexibilidade de (re)organização de processos, organizações e instituições, e por atualizar crescente convergência de tecnologias específicas em sistemas altamente integrados, implicando a interdependência entre biologia e microeletrônica.

É certo que, com qualidades e potencialidades diversas, as tecnologias atualizaram-se nas 
culturas desde muito (desde sempre (?!)), porém, talvez sua presença nunca tenha sido tão evidente, tão expoente e, ao mesmo tempo, tão naturalizada como hoje. As tecnologias constituem-se como extensões do humano que tendem a ser percebidas como se sempre tivessem estado aí, naturalmente, como se não houvesse um antes e um além delas. No entanto, sua potência para ampliar exponencialmente as capacidades humanas também se exerce no sentido de gerar dependências, ou seja, trata-se de algo como se ao desenvolverem habilidades e competências também produzissem atrofias. Assim, importa atentar para as tecnologias e seus empregos de modo mais abrangente para que possam ser adotadas ações que minimizem os reflexos negativos de suas materializações cotidianas.

Tomando-se em particular as tecnologias da comunicação e informação, pode-se dizer que 0 desenvolvimento tecnológico e suas apropriações pelos vários sistemas e/ou subsistemas sociais pressupõem permanentes ajustes, adequações do humano a esse novo ambiente. Assim, se os sujeitos realizam estratégias de modo a apropriarem-se das tecnologias e as reinventam (CERTEAU, 1994), também as tecnologias exigem redimensionamentos diversos nos/dos fazeres cotidianos, portanto, de aspectos dos sistemas sociais, culturais, políticos e ambientais. Como observou Castells (1999, p. 572 ), "os processos de transformação social sintetizados no tipo ideal de sociedade em rede ultrapassam a esfera das relações sociais e técnicas de produção: afetam a cultura e 0 poder de forma profunda." Nesse contexto, sob o Paradigma da Complexidade (MORIN, 2000a, 2000b, 2002) - perspectiva adotada nesta reflexão -, considerando-se que as organizações são partes do todo sociedade (princípio hologramático), pode-se afirmar que essas questões também se fazem presentes no âmbito organizacional, aliás, é provável que as organizações sejam as grandes protagonistas no/ do desenvolvimento tecnológico, bem como na sua apropriação e emprego. Ao observar-se que as organizações assumem centralidade para a sociedade atual, instituindo-se $\mathrm{e}^{1}$ (BOURDIEU, 1996) como modelares, evidencia-se seu poder no sentido de comunicar e fazer reconhecer determinados valores e padrões. Isto é, os sentidos postos em circulação pela comunicação das organizações tendem a desorganizar as redes simbólicas (culturas) dos grupos que constituem a sociedade complexa de modo que, por terem sido perturbadas ${ }^{2}$, necessitem reorganizar-se. Esse

Instituir "[...] é o mesmo que impor um direito de ser que é também um dever ser (ou um dever de ser). É fazer ver "a alguém o que ele é e, ao mesmo tempo, lhe fazer ver que tem de se comportar em função de tal identidade" (BOURDIEU, 1996, p. 100).

Conforme Capra (2002), um sistema vivo somente pode ser perturbado por outro sistema, mas não pode ser determinado por ele. Aqui, ainda com base no autor, a sociedade é compreendida como sistema vivo, assim como as organizações, seus subsistemas. 
poder das organizações, que se realiza de diferentes formas na sociedade, mesmo nos níveis capilares, evidencia a necessidade de reflexão e crítica para não se sucumbir a simples lógica dos interesses privados em detrimento dos interesses públicos.

Frente essa problematização, neste trabalho, sob a perspectiva da comunicação organizacional, reflete-se sobre como as Tecnologias Digitais da Comunicação e Informação (TDCI) - aqui os blogs organizacionais com acesso restrito aos empregados e gestores - têm se constituído, por um lado, em potência para a expressão de ideias, opiniões, impressões e, por outro, em lugar para vigilância, controle e fonte de informações para a exclusão de sujeitos que, de alguma forma, não se "alinham"3 aos valores e à filosofia organizacionais.

\section{TDCI, visibilidade e relações de poder: liberdade e constrangimentos}

A noção de visibilidade é fundamental para esta reflexão, pois que, nas organizações (não parece ser diferente dos demais sistemas políticosócio-culturais), ao acionarem os processos expositivos possibilitados e/ou potencializados pelas TDCI, os sujeitos não apenas adentram no âmbito da "visibilidade mediada" (THOMPSON, 2008), lançando luzes sobre o que expressam, senão que também tomam lugares na arena das disputas por imposições de ideias, valores, verdades, compreensões de mundo. Mesmo que se pudesse dizer que toda expressão realizada nas TDCI sempre é acionada pela nobre ideia do compartilhamento, mesmo que nunca se tratasse de simples exibicionismo, de puro exercício de vaidade, de necessidade/desejo de pertencer e/ ou demarcar espaços, de simples vontade de expressar e tomar parte etc., mesmo assim, não se poderia esquecer que a intenção de compartilhar de quem se expressa sempre pode assumir outras configurações na medida em que a alteridade a perceba ou se aproprie do que foi expresso em outras perspectivas, como, por exemplo, a da expropriação.

Portanto, as TDCI, além de potencializarem a visibilidade do que é exposto e de quem expressa, também se constituem em arena de disputas, em lugar de atualização de diferentes relações de poder. Nessa direção, "a intenção de parodiar a absolutidade solar, de 'brilhar' ou 'reinar', por tempo relativo, em determinado diâmetro de interações, prevalece no anseio por visibilidade no reduto virtual" (TRIVINHO, 2011, p. 123, grifos do autor).

Conforme observa Thompson (2008), 0 desenvolvimento da comunicação mediática liberta a visibilidade dos aspectos espaciais e temporais do aqui e agora; a internet $\mathrm{e}$ outras tecnologias digitais amplificaram e 
complexificaram essas formas de visibilidade.

Destaca que o aumento do fluxo de conteúdo e a ampliação do número de sujeitos que criam e disseminam esse conteúdo, bem como o fato de que 0 controle sobre a circulação desse conteúdo simbólico, no campo da política, torna-se cada vez mais difícil e insustentável. Cabe observar que isso precisa ser relativizado no âmbito organizacional à medida que alguns dos sistemas são fechados (acesso e circulação) ou, pelo menos, restritos à organização.

Thompson (2008, p. 24) destaca que as tecnologias possibilitaram 0 surgimento da "sociedade da autopromoção", em que lideranças políticas e outros sujeitos podem aparecer diante de públicos distantes e desnudar "[...] algum aspecto de si mesmos ou de sua vida pessoal". Mais incisivo, Trivinho (2011, p. 113, grifo do autor) afirma que "o processo civilizatório instituído ao longo do século XX [...] forjou e estabilizou pari passu uma equação social imperativa: a de uma existência (pessoal, grupal, governamental, corporativa etc.) inteiramente condicionada à aparição na visibilidade mediática" $a^{4}$ E complementa: "[...] um existente (indivíduo, grupo, objeto, marca etc.) não subsiste per se; vige, como tal, se, e somente se, nos e através de media, sejam eles de massa, interativos ou híbridos, fixos ou móveis".
Evidenciando importante característica dessa época, Trivinho (2011, p. 114, grifo do autor) assevera que 0 ethos da civilização contemporânea exige que os sujeitos se façam presentes para a alteridade "[...] independentemente de ela conceder ou não a atenção requerida [...] (super)expor-se ou tornar-se visível [...]" na acepção "[...] de existir de alguma forma (como simulacro) perante 0 conjunto dos sentidos percepcionais da alteridade".

Então, a atual configuração das TDCI, além de se constituir em possibilidade de os diferentes sujeitos se tornarem presentes na arena das disputas simbólicas (mesmo as vozes até marginalizadas), também fomenta - e fornece subsídios para que os sujeitos acreditem nisso - 0 desejo de diferenciação. Dessa forma, não se trata de simplesmente participar da cena. "0 que constitui 'capital social' estritamente valorizado [...] é a 'produção continuada de um epicentro mediático' ou o ‘domínio do foco-mainstream do cenário estabelecido"' (TRIVINHO, 2011, p. 116, grifo do autor). Esse "desejo do único" do sujeito atual é, conforme Trivinho (2011, p. 115, grifo do autor), "[...] o desejo de domínio [...] de algum centro de cena mediática e, nela, de reciclagem do próprio (identidade, persona, perfil, estilo, marca etc.), como forma de demonstração distintiva de alguma potência, em algum raio de alcance 
social". Assim, ainda segundo o autor, "0 desejo do único encerra a pulsão ordinária de encenação solo e socialmente reputada em dado contexto de pertencimento (concreto ou imaginário)" (TRIVINHO, 2011, p. 116).

Nessa direção, as manifestações realizadas no âmbito das TDCS não atualizam apenas a ideia de compartilhamento, pois que a noção de "desejo do único" revela a vontade de domínio de cena, de adentrar a esfera de visibilidade para receber as luzes, o que significa, em alguma medida, excluir a alteridade desse mesmo lugar, ainda que não se trate de algo consciente. Conforme Trivinho (2011, p. 121, grifo do autor), em seu âmago, esse desejo contém "[...] uma pulsão irresistível por 'ascendência ofuscante involuntária' em relação à alteridade. [...] 0 imperativo da presença $\mathrm{e}$ a motivação ancestral do desejo nele atuante corresponde a uma 'violência invisível' que, para todos os efeitos [...], não existe [...]". Alerta, ainda, para a inexistência de dolo ou culpa nessa relação.

Entrar ou não em cena, ocupar lugar ou não na esfera de visibilidade pressupõe, em algum grau, mesmo que em nível inconsciente, 0 tensionamento entre ofuscar a alteridade ou ofuscar-se. No contexto atual e sob a perspectiva do "desejo do único", pode-se pensar que a tendência é a de ocupar esse espaço, enquadrando a alteridade nas regiões de menos luz, na periferia da visibilidade. No entanto, 0 fato de estar em cena não significa, por si só, uma boa apresentação de si, uma convincente ocupação de espaço e/ou obter o reconhecimento da alteridade, particularmente daqueles sujeitos, instâncias e/ou instituições que se reconhece como legítimos para reconhecerem (CAILLÉ, 2011). Pode-se pensar em um elástico conjunto de nuances que vai desde os efeitos positivos sobre a alteridade, gerando reconhecimento e aceitação de quem expõe e do que expressa, até seu oposto em que ocorre a rejeição do que foi exposto e a desqualificação do sujeito sob os holofotes. Ocupar esse espaço pode se constituir em importante exercício de poder sobre a alteridade, porém não há garantias de que isso se realize uma vez que a qualidade com que esse espaço é ocupado (forma e conteúdo expresso $)^{5}$, pode ser fator tanto de legitimação quanto de desqualificação do sujeito que ocupa centralidade na cena. Vale lembrar, nesse sentido, que o poder não está estabelecido, somente se dá efetivamente a conhecer no acontecer, na relação, pois que é dispersivo, conforme Foucault (1979).

Foucault (1987) também atentou para as relações entre visibilidade e poder. Referindose às sociedades do mundo antigo, afirmou que sob a perspectiva do espetáculo, poucos se tornavam visíveis para muitos, demonstravam sua força e superioridade de modo exemplar e assim evidenciavam seu poder. Depois, a partir 
do século XVI, essa forma de poder cedeu lugar para novas formas de disciplina, vigilância e registro. Na "sociedade disciplinar" (FOUCAULT, 1987), assume relevo a visibilidade de muitos para poucos. 0 autor emprega a imagem do Panóptico ${ }^{6}$ para demonstrar e aclarar essa forma de exercício de poder em que muitos assumem visibilidade (são vigiados) para poucos, que os controlam. Thompson (2008) critica as análises de Foucault afirmando que o modelo Panóptico negligencia o papel das mídias na sociedade atual. Destaca o fato de a mídia permitir que poucos estejam visíveis para muitos e ressalta que, nessa configuração, fundamentalmente, os que exercem poder é que estão sujeitos a esse novo tipo de visibilidade. Considerando-se as TDCI em sentido complexo, pode-se dizer que as relações entre visibilidade e poder assumem diferentes configurações e exercem-se em várias direções. Os regimes de visibilidade, em contextos variados, são de poucos para muitos, de muitos para poucos, de muitos para muitos, e de poucos para poucos.

Diante disso, a partir do emprego das TDCIs no âmbito das organizações, particularmente os blogs organizacionais, importa refletir sobre que relações de poder e como se estabelecem sob regimes de visibilidade específicos. Para isso, primeiramente, discorre-se sobre a relação subjetividades-organizações.

\section{Organizações e subjetividades: prazer e sofrimento}

A ideia de organização pressupõe associação de sujeitos que, coordenadamente, combinam esforços (habilidades e competências) para a consecução dos objetivos da entidade organizacional, de modo geral considerados objetivos comuns. No entanto, é fundamental evidenciar que também os objetivos particulares dos diferentes sujeitos se atualizam no "ser" organização e, tensionados aos objetivos comuns, a constituem. Portanto, a organização não se reduz aos objetivos comuns.

Como sistemas vivos, as organizações são resultados dinâmicos - permanentemente (re) construídas - das relações estabelecidas pelos sujeitos que nela se realizam como forças em disputa. Em processos dialógicos, esses sujeitos selecionam, circulam e transacionam significação. Dessa forma, mesmo que a organização se exerça em perspectiva disciplinar sobre os vários sujeitos que a constituem, "[...] estabelecendo objetivos e formas de ação organizacionais, não significa que consiga anular e/ou eliminar os objetivos portados por cada sujeito que se associou a outros em organização" (BALDISSERA, 2010, p. 63 ). Mais provável é que esses sujeitos percebam a organização como possibilidade de atingirem seus próprios objetivos e, nessa direção, tendam a agir para que os objetivos organizacionais sejam 
atingidos, pois isso significa também ampliar as possibilidades de atingir os próprios objetivos.

Além de se instituírem como modelares, as organizações representam a possibilidade de realização para os sujeitos. No entanto, assim como têm potência para gerar prazer, também podem gerar muito sofrimento para os que nelas trabalham (CHANLAT, 1996; DEJOURS, 1999, 1996). A atual configuração sociocultural e estrutural torna as organizações um dos mais importantes lugares para que os sujeitos, mediante seu trabalho, consigam demonstrar sua potencialidade criativa e produtiva, desenvolver suas habilidades e competências e, nessa direção, sentirem-se social e culturalmente pertencentes ao sistema. Nas organizações, os sujeitos encontram a possibilidade de realização profissional, o que tende a gerar satisfação e bem-estar.

0 reconhecimento ${ }^{7}$ do trabalho mediante elogios (particularmente os públicos), a avaliação positiva realizada por lideranças e colegas de trabalho sobre ideias apresentadas, 0 sentimento de pertença, 0 atingimento de metas, 0 simbólico associado à organização (a organização ser publicamente reconhecida como referência), o respeito às subjetividades e às diferenças, e as possibilidades de os sujeitos continuarem a se desenvolver (ampliar seus conhecimentos), dentre outras coisas, são fontes de prazer para os sujeitos que laboram nas organizações. Lógico, as sensações de prazer não são permanentes, antes são da qualidade do transitório e exigem constantes confirmações, atualizações.

Quando isso não acontece, as organizações tendem a frustrar as expectativas dos sujeitos, gerando diferentes níveis de sofrimento. Sofrimento compreendido "[...] como o espaço de luta que cobre o campo situado entre, de um lado, 0 'bem-estar' [...] e, de outro, a doença mental ou a loucura" (DEJOURS, 1996, p. 153). Nessa direção, Chanlat (1996, p. 25) observa que as organizações aparecem frequentemente como lugares propícios ao "[...] sofrimento, à violência física e psicológica, ao tédio e mesmo ao desespero não apenas nos escalões inferiores, mas também nos níveis intermediário e superior". 0 autor afirma também que, nesse ambiente rigidamente dominado pela racionalidade instrumental e pelas categorias econômicas estabelecidas, os sujeitos que atuam nas organizações tendem a ser considerados como simples "recursos", algo como materiais que devem ter "rendimento satisfatório", assim como as ferramentas, a matéria-prima, as máquinas.

Diante do exposto, quer parecer que as sensações de prazer e de sofrimento, nas organizações, são faces de subjetividade permanentemente tensionadas. Contextuais, atualizam uma série de aspectos que não dizem respeito somente

Observe-se que, conforme Caillé, o reconhecimento não apenas aciona os sentidos de identificação e valorização, senão que exige "[...] considerar a gratidão, isto é, o reconhecimento de um dom ou de uma doação. As lutas por reconhecimento são, em última instância, lutas para alcançar a posição de doador (e, portanto, de credor)" (2011, p. 36) 
aos procedimentos organizacionais do presente, senão que se relacionam, indelevelmente, à constituição das subjetividades em seu processo psíquico-histórico-sociocultural. Assim, o nível suficiente de reconhecimento (como isso é feito, por quem, em que ambiente, com que palavras, em que intensidade etc.) para gerar prazer a um determinado sujeito provavelmente é diferente do exigido por outro, por mais que possa ser muito semelhante. Da mesma forma, o paradigma de sofrimento de cada sujeito e o nível que cada um é capaz de suportar tendem a ser diversos. Com isso, não se quer relativizar o sofrimento gerado pelas organizações, mas atentar para o fato de que não há uma medida que possa ser aplicada a todos os casos. Além disso, procura-se dar relevo à compreensão de que se, como se disse, as sensações de prazer são transitórias, as de sofrimento, por seu turno, parecem inclinadas a ser mais estáveis ou, pelo menos, a apresentar tempo expandido de realização. Outro aspecto é 0 de que é provável que os sujeitos experimentem, em sua cotidianidade nas organizações, a alternância entre sensações de prazer e sofrimento, até porque níveis elevados de sofrimento tenderiam a gerar doenças crônicas nos sujeitos e a necessidade de seu afastamento de suas rotinas de trabalho (o que não é algo incomum, pelo contrário).

As organizações, conhecedoras dessa tensão, seja por disporem de profissionais especializados ${ }^{8}$ ou pela análise das entrevistas de desligamento, dos relatórios médicos e/ou dos dados estatísticos que demonstram o nível de ausências ao trabalho por doença, bem como pelos processos impetrados contra a organização por empregados que foram afastados (demitidos, aposentados ou que solicitaram desligamento) por doenças do trabalho, tendem a desenvolver e a implementar ações para abrandar os efeitos negativos desse sofrimento, mesmo que, em muitos casos, não passem de simples estratégias para maquiar os problemas. Estratégias essas geralmente acompanhadas de discursos que procuram impor outra visão sobre os fatos ou, pelo menos, minimizar a relevância da situação problemática. Nessa direção, a comunicação organizacional, em particular a dimensão da "organização comunicada" (BALDISSERA, 2009 ), como fala autorizada, tende a ser acionada para, de modo planejado, oferecer informações e imagens de si (organização) objetivando direcionar os processos interpretativos, como se verá a seguir.

\section{Blogs organizacionais: compartilhamento e visibilidade e/ou vigilância e expropriação}

Antes de prosseguir importa dizer que a comunicação organizacional é compreendida como "[...] processo de construção e disputa de sentidos no âmbito das relações 
organizacionais"' (BALDISSERA, 2008, p. 169). Nesse sentido, organizações e sujeitos (neste caso os empregados) são forças em relação que não podem ser subestimadas. Por um lado, considerando-se que os sujeitos em processo de comunicação disputam sentidos, evidencia-se que apesar de as organizações desejarem impor uma dada linha interpretativa (como se disse), não significa que isso realmente ocorra. Por outro, é provável que as organizações, focadas em seus objetivos, procurem conhecer os códigos culturais de seus públicos (em algum nível) para construir e oferecer discursos que, de alguma forma, possam neutralizar as resistências e gerar simpatia. Isto é, trata-se de gerar discursivamente algo como um espelhamento dos valores dos públicos para que, ao reconhecerem seus próprios valores na fala organizacional, tendam a se identificar com ela. A essa luz, importa refletir sobre como as organizações se apropriam das TDCI e as oferecem discursivamente aos empregados e a forma como se exercem sobre tais sujeitos.

\section{Conforme Primo (2008, p. 11), os blogs} organizacionais "são aqueles cujos posts e interações são sobredeterminados pela formalização das relações e sistematização das forças de trabalho em busca de objetivos que delimitam e direcionam a atuação de cada participante do processo". Diferentemente do que acontece na blogosfera em sentido amplo, em que, em princípio, os sujeitos podem expressar livremente (?) suas opiniões, no âmbito das organizações, o norte é a fala autorizada, mesmo que possa se materializar em linguajar informal. Trata-se do "livre desde que". 0 sujeito é livre para expressar-se desde que não ultrapasse 0 âmbito restrito das "medidas" organizacionais, isto é, desde que atente para 0 que a organização quer dizer e permite dizer. "Liberdade condicionada" de expressão.

A ideia de liberdade condicionada atualiza 0 fato de que os sujeitos que atuam nas organizações são portadores da cultura organizacional e, portanto, estão imbuídos de suas prescrições e proscrições de modo que tenderão a observá-las quando de suas manifestações nos blogs. Além disso, como forma mais pontual de orientar os usos e restringir os equívocos, os excessos e as tentações, também são oferecidas normas de uso dos $b_{l o g} s^{10}$. Com o cruzamento desses processos, ações informativas e, se necessário, com algumas penalizações exemplares (retratações públicas, constrangimentos em reuniões com lideranças e, em casos extremos, demissões) é provável que, rapidamente, as organizações consigam a "docilidade expressiva" desses sujeitos mediante

9 Essa compreensão foi apresentada em Baldissera, 2000, e reapresentada/complexificada em vários trabalhos posteriores (BALDISSERA, 2004, 2008, 2009, 2010, dentre outros).

10 Considerando o blog como meio para dar visibilidade às informações no âmbito das organizações, Cipriano (2006) alerta para a necessidade de que sejam estabelecidas políticas de uso e o monitoramento do que é postado. 
o desenvolvimento, dentre outras coisas, de estratégias de autocensura para expressarem-se em blogs organizacionais.

Considerando-se que os blogs organizacionais são meios autorizados para a materialização de processos de comunicação organizacional, parece lógico que as organizações exerçam algum nível de acompanhamento e controle sobre o que os diferentes sujeitos aí expressam de maneira a que essas falas não se contraponham à filosofia organizacional. Com isso, evidencia-se o fato de não se reconhecer problemas em os blogs organizacionais estarem atrelados aos objetivos das organizações e serem monitorados para isso. Além disso, cabe destacar a importância dos blogs organizacionais de acesso restrito (neste caso restrito aos empregados e lideranças) para a comunicação organizacional à medida que ampliam e dinamizam a circulação de informações, têm potência para processos interativos, podem estimular a participação e expressão de opiniões, podem qualificar processos de decisão mediante a discussão qualificada, podem fomentar os processos colaborativos, são importantes para os processos de gestão de conhecimento, têm baixo custo para implementação etc. (CIPRIANI, 2006; OLIVEIRA, 2010; PRIMO, 2008; TERRA, 2008). Então, sob a perspectiva dos interesses organizacionais, parece inquestionável a relevância dos blogs.

No entanto, acredita-se fundamental lançar outro olhar sobre os empregos dos blogs na comunicação organizacional. Uma das questões refere-se à liberdade de expressão. No nível do senso comum os sujeitos tendem a perceber as TDCI e, em particular, os blogs como lugar e possibilidade para exposições de si e expressões livres. Inclinam-se a experimentar forte sensação de liberdade e mesmo de impunidade no expressar-se nas/por meio das TDCI, como se estivessem protegidos dos olhos da alteridade. 0 desejo de visibilidade (exposição, exibição, expressão irrestrita), de "ocupar a cena" (TRIVINHO, 2011), não apenas atualiza o desejo de, em algum nível, ofuscar a alteridade, mas também o desejo de que a alteridade se constitua em espectadora dócil, entusiasmada com a centralidade que 0 sujeito assume na cena. Além disso, o sujeito parece agir por esquecimentos, como por exemplo, o fato de que a alteridade interpreta a partir de seu próprio lugar, julga, qualifica, desqualifica, legitima, põe em suspenso e/ou defenestra, bem como o de que ela também deseja a centralidade da cena.

Portadores dessa compreensão, quando dos usos dos blogs organizacionais, é provável que esses sujeitos cometam "deslizes" - com diferentes implicações - aos olhos dos gestores. Sob a falsa sensação de liberdade (trata-se de liberdade condicionada), o discurso organizacional tende a estimular os empregados a participarem, a exporem suas opiniões, porém não revela que também se trata de mecanismo de vigilância, e até de controle, seja pelos gestores, seja pelos próprios colegas de trabalho. Importa atentar, 
também, para o fato de que ao se manifestar (dizer algo), um sujeito não apenas fala sobre o objeto de sua opinião, mas também se dá a conhecer, diz de si próprio. Assim, considerandose que as TDCI (aqui, em particular, os blogs organizacionais) potencializam o que é dito, por exemplo, um comentário infeliz que seria realizado para um colega ou alguns colegas em uma reunião, passa a ser do conhecimento de todos na organização. Assim, o tornar-se presente, o ocupar a cena como lugar de honra também pode se constituir no seu oposto, na desqualificação do sujeito.

Da mesma forma, o discurso organizacional, cada vez mais, estimula o compartilhamento (como é comum sua prática nas redes sociais digitais em sentido amplo, e tem sido qualificado positivamente pelos diferentes grupos sociais) de informações, ideias, fazeres. Mas o que isso significa? Que intenções o discurso do compartilhar esconde? Primeiramente, importa dizer que há evidente estratégia da organização na perspectiva da gestão do conhecimento: trata-se de uma forma de tornar explícito o conhecimento que era tácito. Tornar 0 conhecimento comum, não apenas implica no fato de a organização reter e potencializar o conhecimento construído, mas também em neutralizar o poder dos empregados que detinham tal conhecimento - afinal, saber é poder (FOUCAULT, 1979); se todos sabem, nenhum empregado é indispensável, nenhum empregado pode tornar a organização refém de seu saber.
Outro aspecto é o fato de que esse compartilhar conhecimento e ideias pode representar para a organização a economia de grandes valores que teriam que ser investidos para contratação de especialistas para o desenvolvimento de sistemas, tecnologias, produtos. Questiona-se, então: como a organização recompensa as ideias dos empregados? Em que medida isso não consiste em dissimulados processos de expropriação?

Ainda sobre 0 compartilhar nos blogs organizacionais, a fala oficial tende a (re)afirmar que é a possibilidade de gerar reconhecimento para os que apresentam boas ideias, boas opiniões, resolvem problemas. Isso, em si, é bom, pois, como se viu, o reconhecimento gera níveis de prazer. 0 problema é 0 fato de que essa é apenas uma face da moeda. A questão é: Como ficam os sujeitos que, acreditando apresentar boas ideias, expõem-se publicamente com ideias equivocadas, propostas ingênuas ou até obtusas, revelando baixos níveis de compreensão e conhecimento? Se o reconhecimento de alguns gera alguns níveis de prazer, a desqualificação, a ridicularização de outros certamente gera elevados níveis de sofrimento. Mais do que isso, pode implicar, inclusive, em ações veladas de assédio moral.

Essas reflexões revelam como as organizações se apropriam dos códigos culturais da sociedade, em particular de seus públicos, e passam a empregá-los estrategicamente no sentido de gerar espelhamentos e identificações. Se é 
possível afirmar que os blogs corporativos agilizam a circulação de informações e também podem fomentar o diálogo, também é possível dizer que seus usos pelas organizações não se restringem a isso. 0s discursos da participação, do compartilhamento, da liberdade de expressão tendem a escamotear outras questões implicadas nesses processos, conforme se ressaltou. Expor ideias, também significa expor-se e quando essa exposição é potencializada pelos blogs, assumese visibilidade pública e tudo o que isso implica. 0cupa-se espaço em cena, recebe-se as luzes, é certo, mas o estar na região de visibilidade também se traduz em avaliações, qualificações e controles, reconhecimento e/ou exclusão. Então, não se trata de liberdade de expressão, mas de algo como "liberdade (?) condicionada e vigiada".

De modo semelhante, sob a égide do compartilhar, realizam-se intenções estratégicas que pouco tem a ver com compartilhar. Antes, o compartilhar restringe-se ao compartilhamento das ideias e do conhecimento dos outros. Afinal, também é isso que as organizações procuram na perspectiva da gestão do conhecimento e a comunicação organizacional é empregada para potencializar as possibilidades e as probabilidades desse objetivo ser alcançado.

\section{Referências}

BALDISSERA, R. Comunicação organizacional: o treinamento de recursos humanos como rito de passagem. São Leopoldo: Unisinos, 2000.

BALDISSERA, R. Imagem-conceito: anterior à comunicação, um lugar de significação. 2004. Tese (Doutorado em Comunicação Social) - Pontifícia Universidade Católica do Rio Grande do Sul, Porto Alegre, 2004.

BALDISSERA, R. Uma reflexão possível a partir do paradigma da complexidade. In OLIVEIRA, I. L.; SOARES, A. T. N. Interfaces e tendências da comunicação no contexto das organizações. São Caetano do Sul, 2008, p. 149-177.

BALDISSERA, R. Comunicação organizacional na perspectiva da complexidade. Organicom - Revista Brasileira de Comunicação Organizacional e Relações Públicas. São Paulo, v. 6, n. 10/11, p. 115-120, 2009. Disponível em < http://www.revistaorganicom.org.br/ sistema/index.php/organicom/article/view/194/294>. Acesso em: 20 fev. 2012.

BALDISSERA, R. Organizações como complexus de diálogos, subjetividades e significação. In: KUNSCH, M. M. K. A comunicação como fator de humanização das organizações. São Caetano do Sul, SP: Difusão, 2010. p. 61-76.

BOURDIEU, P. A economia das trocas lingüísticas: 0 que falar quer dizer. São Paulo: USP, 1996.

CAILLÉ, A. Capital social, reconhecimento e dádiva. In: MARQUES, Â.; MATOS, H. (Org.). Comunicação e política: capital social, reconhecimento e deliberação pública. São Paulo: Summus, 2011. p. 19-38.

CAPRA, F. As conexões ocultas: ciência para uma vida sustentável. 2. ed. São Paulo: Cultrix, 2002.

CASTELLS, M. A sociedade em rede. São Paulo: Paz e Terra, 1999. v. 1.15 reimpressão.

CERTEAU, M. A invenção do cotidiano. Petrópolis, RJ: Vozes, 1994.

CHANLAT, J. Por uma antropologia da condição humana nas organizações. In CHANLAT, J. (Coord.). 0 indivíduo na organização: dimensões esquecidas. São Paulo: Atlas, 1996. p. 21-45. 
CIPRIANI, F. Blog corporativo. São Paulo: Novatec, 2006.

DEJOURS, C. A banalização da injustiça social. Rio de Janeiro: FGV, 1999.

DEJOURS, C. Uma nova visão do sofrimento humano nas organizações. In: CHANLAT, J. (Coord.). 0

indivíduo na organização: dimensões esquecidas. São Paulo: Atlas, 1996. p. 149-73.

FOUCAULT, M. Vigiar e punir: o nascimento da prisão. Petrópolis, RJ: Vozes, 1987.

FOUCAULT, M. Microfísica do poder. 12 ed. Rio de Janeiro: Graal, 1979.

MORIN, E. Meus demônios. Rio de Janeiro: Bertrand Brasil, 2000a.

MORIN, E. Ciência com consciência. 4. ed. Rio de Janeiro: Bertrand do Brasil, 2000b.

MORIN, E. 0 método 4. 3. ed. Porto Alegre: Sulina, 2002.

OLIVEIRA, R. de. Blogs internos na comunicação organizacional. In: CONGRESSO BRASILEIRO DE CIÊNCIAS DA COMUNICAÇÃO, 32., 2010, Caxias do Sul. Anais... Caxias do Sul: Intercom/UCS, 2010. Disponível em: < http://www.intercom.org.br/papers/ nacionais/2010/resumos/R5-2810-1.pdf > . Acesso em: 10 jan. 2012.

PRIMO, A. Os blogs não são diários pessoais online: matriz para a tipificação da blogosfera. Revista Famecos, Porto Alegre, v. 1, n. 36, p. 122-128, 2008.

TERRA, C. F. Blogs corporativos: modismo ou tendência? São Caetano do Sul, SP: Difusão, 2008.

THOMPSON, J. B. A nova visibilidade. Revista Matrizes, São Paulo, v. 1, n. 2, p. 15-38, 2008. TRIVINHO, E. Visibilidade mediática, melancolia do único e violência invisível na cibercultura. Revista Matrizes, São Paulo, v. 4, n. 2, p. 111-125, 2011. 
Organizational communication, tecnologies and surveillance: between profesional achievement and suffering

\section{Abstract}

From the perspective of Organizational

Communication, aims to reflect on the tension that materializes in collaborative processes, particularly those that are characterized by, through the use of organizational blogs, giving visibility to knowledge/ informations from different employees in the ambit of their organizations, as well as on appropriations that these same organizations do what is exposed. In this sense, it's possible to think of processes that enhance knowledge through collaboration of different subjects, but also in processes of surveillance and control processes over such subject. Attentive to the fact that organizations, as a place of realization of the subjects, these same processes, constitute, on the one hand, as a possibility for qualified exposure of these subjects, generating recognition / pleasure, and, on the other hand, the disqualified exposure, causing suffering (DEJOURS, 1996, 1999).

\section{Keywords}

Organizational communication. Digital Technologies of communication and information. Visibility. Surveillance. Suffering.

\section{Comunicación organizacional, tecnologías y vigilancia: entre la realización profesional y el sufrimiento}

\section{Resumen}

Desde la perspectiva de la Comunicación Organizacional, se tiene como objetivo reflexionar sobre la tensión que se materializa en los procesos de colaboración, en particular aquellos que se caracterizan por, a través del uso de los blogs organizacionales, dar visibilidad a los conocimientos/informaciones de diferentes empleados en el ámbito de sus organizaciones, así como sobre las apropriaciones que estas mismas organizaciones hacen de lo expuesto. En este sentido, se puede pensar en procesos que potencializan el conocimiento a través de la colaboración de los diferentes sujetos, sino también de la vigilancia y del control sobre tales sujetos. Se atenta al hecho de que las organizaciones, como lugar de realización de los sujetos, en estos mismos procesos, se constituyen, por una parte, como una posibilidad de exposición calificada de estos sujetos, generando reconocimiento/placer, y, por otro lado, de exposición descalificada, causando sufrimiento (DEJOURS, 1996, 1999).

\section{Palabras-Clave}

Comunicación organizacional. Tecnologías digitales de la información y comunicación. Visibilidad.

Vigilancia. Sufrimiento. 


\section{Expediente}

A revista E-Compós é a publicação científica em formato eletrônico da Associação Nacional dos Programas de Pós-Graduação em Comunicação (Compós). Lançada em 2004, tem como principal finalidade difundir a produção acadêmica de pesquisadores da área de Comunicação, inseridos em instituições do Brasil e do exterior.

\section{E-COMPÓS I www.e-compos.org.br I E-ISSN 1808-2599}

Revista da Associação Nacional dos Programas

de Pós-Graduação em Comunicacão.

Brasília, v.17, n.2, mai./ago. 2014.

A identificação das edições, a partir de 2008

passa a ser volume anual com três números.

\section{CONSELHO EDITORIAL}

Afonso Albuquerque, Universidade Federal Fluminense, Brasil Alberto Carlos Augusto Klein, Universidade Estadual de Londrina, Brasil Alex Fernando Teixeira Primo, Universidade Federal do Rio Grande do Sul, Brasil Rio Grande do Sul, Brasi

Ana Gruszynski, Universidade Federal do Rio Grande do Sul, Brasil Ana Silvia Lopes Davi Médola, Universidade Estadual Paulista, Brasil André Luiz Martins Lemos, Universidade Federal da Bahia, Brasi Ângela Freire Prysthon, Universidade Federal de Pernambuco, Brasil Antônio Fausto Neto, Universidade do Vale do Rio dos Sinos, Brasil Antonio Carlos Hohlfeldt, Pontifícia Universidade Católica do Rio Grande do Sul, Brasil Antonio Roberto Chiachiri Filho, Faculdade Cásper Líbero, Brasi Arlindo Ribeiro Machado, Universidade de São Paulo, Brasil Arthur Autran Franco de Sá Neto, Universidade Federal de São Carlos, Brasil Benjamim Picado, Universidade Federal Fluminense, Brasil César Geraldo Guimarães, Universidade Federal de Minas Gerais, Brasil Cristiane Freitas Gutfreind, Pontifícia Universidade Católica do Rio Grande do Sul, Brasil Denilson Lopes, Universidade Federal do Rio de Janeiro, Brasil Denize Correa Araujo, Universidade Tuiuti do Paraná, Brasi Edilson Cazeloto, Universidade Paulista , Brasil

Eduardo Vicente, Universidade de São Paulo, Brasil Eneus Trindade, Universidade de São Paulo, Brasil Erick Felinto de Oliveira, Universidade do Estado do Rio de Janeiro, Brasi Florence Dravet, Universidade Católica de Brasília, Brasil Gelson Santana, Universidade Anhembi/Morumbi, Brasi Gilson Vieira Monteiro, Universidade Federal do Amazonas, Brasil Gislene da Silva, Universidade Federal de Santa Catarina, Brasil Guillermo Orozco Gómez, Universidad de Guadalajara Gustavo Daudt Fischer, Universidade do Vale do Rio dos Sinos, Brasil Hector Ospina, Universidad de Manizales, Colômbia Herom Vargas, Universidade Municipal de São Caetano do Sul, Brasil Ieda Tucherman, Universidade Federal do Rio de Janeiro, Brasil Inês Vitorino, Universidade Federal do Ceará, Brasil Janice Caiafa, Universidade Federal do Rio de Janeiro, Brasil Jay David Bolter, Georgia Institute of Technology Jeder Silveira Janotti Junior, Universidade Federal de Pernambuco, Brasi João Freire Filho, Universidade Federal do Rio de Janeiro, Brasil John DH Downing, University of Texas at Austin, Estados Unidos Ana Carolina Damboriarena Escosteguy, Pontifícia Universidade Católica do

José Afonso da Silva Junior, Universidade Federal de Pernambuco, Brasil José Carlos Rodrigues, Pontifícia Universidade Católica do Rio de Janeiro, Brasil José Luiz Aidar Prado, Pontifícia Universidade Católica de São Paulo, Brasil José Luiz Warren Jardim Gomes Braga, Universidade do Vale do Rio dos Sinos, Brasil Juremir Machado da Silva, Pontifícia Universidade Católica do Rio Grande do Sul, Brasil Laan Mendes Barros, Universidade Metodista de São Paulo, Brasil Lance Strate, Fordham University, USA, Estados Unidos Lorraine Leu, University of Bristol, Grã-Bretanha Lucia Leão, Pontifícia Universidade Católica de São Paulo, Brasil Luciana Panke, Universidade Federal do Paraná, Brasil Luiz Claudio Martino, Universidade de Brasília, Brasil Malena Segura Contrera, Universidade Paulista, Brasil Márcio de Vasconcellos Serelle, Pontifícia Universidade Católica de Minas Gerais, Brasil Maria Aparecida Baccega, Universidade de São Paulo e Escola Superior de Propaganda e Marketing, Brasil Maria das Graças Pinto Coelho, Universidade Federal do Rio Grande do Norte, Brasil Maria Immacolata Vassallo de Lopes, Universidade de São Paulo, Brasil Maria Luiza Martins de Mendonça, Universidade Federal de Goiás, Brasil Mauro de Souza Ventura, Universidade Estadual Paulista, Brasil Mauro Pereira Porto, Tulane University, Estados Unidos Nilda Aparecida Jacks, Universidade Federal do Rio Grande do Sul, Brasil Paulo Roberto Gibaldi Vaz, Universidade Federal do Rio de Janeiro, Brasil Potiguara Mendes Silveira Jr, Universidade Federal de Juiz de Fora, Brasil Renato Cordeiro Gomes, Pontifícia Universidade Católica do Rio de Janeiro, Brasil Robert K Logan, University of Toronto, Canadá

Ronaldo George Helal, Universidade do Estado do Rio de Janeiro, Brasil Rosana de Lima Soares, Universidade de São Paulo, Brasi Rose Melo Rocha, Escola Superior de Propaganda e Marketing, Brasil Rossana Reguillo, Instituto de Estudos Superiores do Ocidente, Mexico Rousiley Celi Moreira Maia, Universidade Federal de Minas Gerais, Brasi Sebastião Carlos de Morais Squirra, Universidade Metodista de São Paulo, Brasil Sebastião Guilherme Albano da Costa, Universidade Federal do Rio Grande do Norte, Brasil

Simone Maria Andrade Pereira de Sá, Universidade Federal Fluminense, Brasi Tiago Quiroga Fausto Neto, Universidade de Brasília, Brasil Suzete Venturelli, Universidade de Brasília, Brasil Valerio Fuenzalida Fernández, Puc-Chile, Chile Veneza Mayora Ronsini, Universidade Federal de Santa Maria, Brasil Vera Regina Veiga França, Universidade Federal de Minas Gerais, Brasil

\section{COMISSÃO EDITORIAL}

Cristiane Freitas Gutfreind I Pontifícia Universidade Católica do Rio Grande do Sul, Brasil Irene Machado I Universidade de São Paulo, Brasil

Jorge Cardoso Filho I Universidade Federal do Reconcavo da Bahia, Brasil / Universidade Federal da Bahia, Brasil

CONSULTORES AD HOC

Adriana Amaral, Universidade do Vale do Rio dos Sinos, Brasil

Alexandre Rocha da Silva, Universidade Federal do Rio Grande do Sul, Brasi Arthur Ituassu, Pontifícia Universidade Católica do Rio de Janeiro, Brasil Bruno Souza Leal, Universidade Federal de Minas Gerais, Brasil Elizabeth Bastos Duarte, Universidade Federal de Santa Maria, Brasil Francisco Paulo Jamil Marques, Universidade Federal do Ceará, Brasil Maurício Lissovsky, Universidade Federal do Rio de Janeiro, Brasil Suzana Kilpp, Universidade do Vale do Rio dos Sinos, Brasil Vander Casaqui, Escola Superior de Propaganda e Marketing, Brasil

EDIÇÃO DE TEXTO E RESUMOS I Susane Barros SECRETÁRIA EXECUTIVA I Helena Stigger EDITORAÇÃo ELETRÔNICA I Roka Estúdio
COMPÓS I www.compos.org.br

Associação Nacional dos Programas de Pós-Graduação em Comunicação

Presidente

Eduardo Morettin

Universidade de São Paulo, Brasil

eduardomorettin@usp.br

Vice-presidente

Inês Vitorino

Universidade Federal do Ceará, Brasil

ines@ufc.br

Secretária-Geral

Gislene da Silva

Universidade Federal de Santa Catarina, Brasil

gislenedasilva@gmail.com 